\title{
Imaginarios fundantes y desafíos institucionales: la refundación de la carrera de Sociología de la UBA en los ochenta y noventa
}

Foundational imaginaries and institutional challenges: The re-foundation of the Sociology career at the UBA over the eighties and nineties

\section{Cecilia Civallero}

Facultad de Ciencias Sociales de la Universidad de Buenos Aires (FSOC, UBA). Universidad de Tres de Febrero (UNTREF). Instituto de Investigaciones Gino Germani (IIGG), Argentina ceciliaciva@gmail.com

\author{
Lautaro Lazarte \\ Facultad de Ciencias Sociales, Universidad de Buenos Aires (FSOC, UBA). Universidad Nacional \\ de San Martin (IDAES-UNSAM). Becario Doctoral UBACyT. Instituto de Investigaciones Gino \\ Germani (IIGG), Argentina \\ llazarte@live.com.ar
}

\begin{abstract}
RESUMEN:
El presente artículo analiza un momento de refundación institucional acaecido en la carrera de Sociología de la Universidad de Buenos Aires luego del retorno al orden democrático en Argentina en el año 1983. Esto implicó la puesta en marcha de un largo proceso de renovación de su planta docente y reformulación de su plan de estudios. Nos proponemos aquí describir este momento, mientras transcurría un proyecto de normalización para toda la Universidad, se creaba la Facultad de Ciencias Sociales y se arribaba al contexto de reformas neoliberales de los años noventa. Haremos uso de documentos institucionales y testimonios, intentando dar voz a una memoria institucional enfocada en el significado que le han otorgado (y le otorgan) sus protagonistas. Nuestras reflexiones finales indican que existieron pugnas políticas, desafíos académicos y dificultades económicas, mientras se recuperaban viejos idearios como fundantes y legítimos, refutando la extendida idea de un pluralismo reinante, el cual solo se reflejó en la oferta de materias optativas.
\end{abstract}

Palabras ClaVE: Sociología, Universidad de Buenos Aires, Años ochenta y noventa, Refundación, Institucionalización.

\section{Abstract:}

The present article analyzes the institutional foundation moment which took place in 1983 in the Sociology degree of the Buenos Aires University after the return of the democratic order in Argentina. This event set in motion a long process of teaching staff renovation and study curriculum reformulation. We propose to describe that particular event, in a context of normalization in the whole university, the foundation of the Social Sciences School and the arrival of the neoliberal reforms in the nineties. We are going to use institutional documents as well as testimonies giving voice to institutional memory and looking particularly to the meanings given (and still imparted) by their protagonists. Our final reflections point that political struggles, academic challenges and economical difficulties have occurred while old foundational ideas were recovered as legitim. ese concepts refused the extended idea about the existence of a mainstream pluralism, which was only reflected in the elective courses offering.

KEYwORDs: Sociology, Universidad de Buenos Aires, Eighties and nineties, Refoundation, Institutionalisation. 


\section{1-INTRODUCCIÓN ${ }^{1}$}

Este artículo indaga sobre un proceso acontecido en la carrera de Sociología de la Universidad de Buenos Aires (UBA) luego de la recuperación de la democracia en nuestro país en el año 1983. Es a partir de entonces que la carrera logra, lentamente, normalizar su funcionamiento y consolidar su presencia como institución, en un marcado contraste con la trayectoria compleja y accidentada que la había caracterizado desde su creación en 1957 (Sidicaro, 1993; Blois, 2017). Consideramos que este momento puede analizarse como una "refundación", tanto por el cambio y la estabilidad que tomó el funcionamiento de la institución, así como también por los propios testimonios de los protagonistas que tuvieron a su cargo dicha tarea y que así definieron esa coyuntura. Este proceso -que se llevó adelante en un contexto signado por la efervescencia política y la precariedad económica- implicó no solamente la renovación de la planta docente y el plan de estudios, sino también la incorporación de la carrera dentro de una nueva unidad académica, la Facultad de Ciencias Sociales (en adelante FCS).

Luego de una caracterización de la refundación de la carrera, describiremos de qué modo este proceso afectó a la vida de la institución y a la disciplina, así como también la creación de la FCS y el contexto de las reformas neoliberales en los años noventa. Nos proponemos sumar un aporte a esta reconstrucción, desde una mirada enfocada en el significado que le han otorgado (y le otorgan) los actores al momento histórico analizado, a través de testimonios y documentos institucionales, como publicaciones emitidas por la propia carrera, la Facultad, entre otras instancias. A su vez, nos centramos en fuentes novedosas, que permiten dar voz a una memoria institucional que pueda transmitirnos cuáles han sido las singularidades del proceso descrito, sus desafíos, limitaciones y herencias para el enriquecimiento de los debates actuales. ${ }^{2}$

Pese a la importancia de este hito, y a la relevancia que tendría para la propia historia de la disciplina a nivel local, es necesario señalar que las publicaciones que han acometido una reconstrucción sobre los actores y procesos que convivieron dentro de ese espacio institucional han realizado indagaciones más detalladas para el período 1957-1976 (Rubinich, 1999; González, 2000; Noé, 2005; Blanco, 2006; Pereyra, 2007 y 2010; Blois, 2017). Al situarse sobre las décadas de 1980 y 1990, el interés de los investigadores se encuentra focalizado en los aportes de la disciplina y de los actores participantes del proceso de refundación a la agenda de la transición democrática (Lesgart, 2003; Casco, 2007; Baldoni, 2008; Alfredo, 2014; Freiburn, 2014; Garategaray, 2018; Vezzetti, 2018);también se concentra en el impacto de las reformas neoliberales de los años 90 sobre los campos de inserción profesional de los sociólogos (Rubinich, 2001; Beltrán, 2005; Rubinich y Beltrán, 2010; Blois, 2014).

Dentro de este balance de investigaciones podemos citar unas pocas excepciones que han trabajado sobre la carrera de Sociología en las décadas del 80 y 90 (Mancuso, 2011; Blois, 2009 y 2017). Sin embargo, señalamos que el foco de estos trabajos se sitúa sobre el tratamiento de las reformas curriculares y sobre los cambios en la planta docente en el período comprendido entre el inicio de la gestión normalizadora en la UBA (marzo de 1984) y la reforma del plan de estudios (año 1988). Recientemente, Blois (2017) ha dedicado sendos capítulos al análisis de la dinámica y los procesos que tuvieron lugar en el interior de la carrera durante ambas décadas. A partir delos avances logrados en sus trabajos previos, articula una serie de dimensiones (institucional, disciplinar, profesional) para dar cuenta de manera global de las diversas dinámicas y coyunturas, tanto locales como internacionales, que impactaron sobre esta institución. Sin embargo, y a pesar de los valiosos aportes que estos antecedentes en su conjunto realizaron, es necesario señalar que ninguno de ellos se centra en un relato institucional o en los testimonios concretos de los participantes. De allí la importancia de las fuentes 
que se han seleccionado para este trabajo, por medio de las cuales entendemos que se despliega un aporte novedoso: aprehender los sentidos, memorias y significados que la institución y sus miembros (re)construyen sobre el período seleccionado, analizándolo desde el relato que las fuentes nos proveen.

Finalmente, la estructuración del trabajo se halla dividida en cuatro apartados. En el primero detallamos la metodología y las fuentes que hemos utilizado para este trabajo, y precisamos conceptos importantes para nuestra indagación como son los de memoria institucional, refundación e institucionalización. En el segundo nos dedicamos a describir el momento posterior a la reapertura de la carrera de Sociología, su consiguiente período de normalización, el cual estuvo caracterizado por la creación de la FCS, de nuevas carreras en dicha facultad, y por la aprobación de un nuevo plan de estudios. En el tercer apartado seguiremos analizando el proceso de institucionalización de la carrera de Sociología enfocado en los años noventa, un contexto signado por la crisis económica y los proyectos de reforma en el Estado y en la universidad, e intentaremos reseñar los efectos que ha tenido sobre la institución a través del modo en que ella misma lo describe. Finalmente, concluimos nuestro trabajo señalando los principales hallazgos y su proyección hacia futuras indagaciones.

\section{2- CONTEXTO CONCEPTUAL Y FUENTES UTILIZADAS}

Las fuentes escogidas y el modo a través del cual han sido compendiadas contribuyen a describir un proceso vivido por la institución a través de sus voces. Se han tenido en cuenta los testimonios de algunos de sus protagonistas, así como también sus publicaciones institucionales y eventos concretos. Es por eso que los materiales seleccionados para el presente trabajo son: los primeros tres boletines (el primero publicado en octubre de 1988, el segundo en noviembre-diciembre del mismo año y el tercero en mayo-junio de 1989) y los informes de gestión (años 1992 y 1994) de la FCS; los boletines llamados "NoticiaS" de la Dirección de la carrera de Sociología (años 1994 -abril, mayo, julio, agosto, septiembre y octubre- y 1996 -agosto y septiembre-); por último, el dossier titulado "Situación presupuestaria de la carrera", publicado en mayo de 1999 por gente de la misma. Se han considerado las entrevistas realizadas a diversos directores de la carrera de Sociología, con motivo de sus 60 años, llevadas a cabo por esta misma institución y publicadas en su página de Facebook. ${ }^{3}$ Finalmente, hemos efectuado dos entrevistas a quienes fueron directores de carrera en la década del ochenta y del noventa: Juan Pegoraro (1988-1991) ${ }^{4}$ y Néstor Cohen (1994-1998). ${ }^{5}$

Estas fuentes han sido escogidas porque contribuyen a analizar los tránsitos de la carrera y la facultad en las décadas del ochenta y noventa. Asimismo, hemos delimitado este marco temporal en función de tomar una cantidad de años considerable para analizar, de manera extendida, un proceso de reorganización institucional. A su vez, no podemos desconocer el advenimiento del neoliberalismo -y sus lógicas dentro del sistema universitario- en nuestro país, en un momento prácticamente contemporáneo a la creación de la FCS. El dossier del año 99, que hace referencia a la situación presupuestaria de la carrera, nos brinda, por tanto, un punto de cierre, ya que aporta datos que contribuyen a analizar un final de década y refleja -de manera retrospectiva- la crisis que sucede al período de normalización. Por otro lado, tanto las entrevistas a quienes han ocupado cargos de gestión en la Facultad y en la carrera de Sociología como los "Boletines de Información" y los informes de gestión nos proveen los relatos y referencias directas de aquellos que han tenido a su cargo la refundación y la creación de una institución académica de gran envergadura. El uso de los testimonios, pasados y actuales, nos habilita a sumar y emparentar este trabajo a aquellos esfuerzos realizados por reconstruir una memoria histórica que nos permita discernir el perfil actual del graduado de Sociología. Cardoso (2016) constituye un antecedente significativo, ya que examina el $50^{\circ}$ aniversario de la carrera de Sociología de la UBA y nos propone "entender la conmemoracio\#n como estructura que estructura el recuerdo institucional”, por lo cual describe una memoria histo\#rica como produccio\#n institucional, como espacios y momentos excepcionales que dan cuenta de dicha producción.

Ahora bien, inevitablemente, y a raíz de lo poco que se conserva como material de archivo en nuestra facultad, hemos realizado un recorte metodológico de esta voz institucional. Consideramos que la definición 
misma de institución de la cual partimos permite considerar, y hace posible describir, innumerables acontecimientos y actores que se mueven y desarrollan dentro y fuera de la misma. Docentes, personal administrativo (no docente), alumnos y agentes que participan de la vida cotidiana de la facultad, todos conforman las prácticas sociales que hacen a la institución misma con sus relaciones sociales diversas, y que forman tanto lo instituyente como lo instituido. Es por eso que aquí la institución no significa algo dado, inmutable, o simplemente un momento histórico que pretendemos traer al presente como una imagen estática y abarcable. En palabras de Castoriadis (2013), "la institución es una red simbólica, socialmente sancionada, en la que se combinan, en proporción variables, un componente funcional y un componente imaginario" (p. 211).

Si bien podríamos haber seleccionado otras voces o producciones, el recorte que aquí realizamos se basa en los documentos emitidos por la propia facultad, pero también consideramos el relato de sus autoridades, como máximos representantes institucionales de aquella. Esto se debe a los objetivos que nos propusimos: no se trata de transcribir un relato que es reflejo de un pasado, sino de reconstruir a la institución como algo a erigir y como un espacio de imaginarios sociales, algo que puede existir solo a través de un "mundo de significaciones", las cuales no son todas explícitas ni son ajenas a un contexto. Esto se debe a que la sociedad instituye en cada momento un mundo como su mundo, y el sostenimiento de sus significaciones imaginarias es lo que mantiene unido a un grupo social, le confiere una unidad y una identidad (p. 566). Esas significaciones son las que intentaremos esclarecer considerando un momento relevante como fue la reapertura de la carrera y su incorporación a una nueva unidad, la FCS. En este primer rastreo, sumar testimonios actuales a los documentos contemporáneos al suceso fue otra decisión metodológica tomada para enriquecer la descripción y generar un debate sobre la historia tal como se vive y recuerda hoy (volveremos sobre esto en este apartado).

Para retomar el punto señalado más arriba, diremos que la recuperación de estos documentos no ha sido una tarea sencilla. A partir de lo expuesto por Lila Caimari (2017), señalaremos que la falta de "cultura de archivo" y los escasos esfuerzos de preservación de documentación y testimonios sobre el accionar y funcionamiento de diversas instituciones en nuestro país -en nuestro caso la carrera de Sociología y la Facultad de Ciencias Sociales- ha sido uno de los principales obstáculos que hemos encontrado a la hora de constituir el conjunto de fuentes con las que trabajamos. Estas cuestiones son el reflejo no solo de la inexistencia e inadecuación de políticas de mantenimiento, control y acceso del patrimonio documental, sino también de cierta prescindencia por parte de las autoridades responsables de las instituciones $-\mathrm{y}$, de manera más general, de la comunidad sociológica toda- en torno a la preservación de materiales que dan cuenta de su propia historia. Si bien existen ciertas iniciativas tendientes a organizar un archivo institucional de la carrera, ${ }^{6}$ su desarrollo se encuentra aún en proceso de consolidación. Esto dificulta la llegada a los documentos referidos ala misma, dado que debe accederse a ellos a través de una suerte de "acceso informal".

Consideramos asimismo que es necesario tener en cuenta ciertas salvedades sobre el trabajo con fuentes que analizan la historia reciente. Sobre todo porque los sentidos sobre el pasado son saberes en constante reconstrucción y actualización, plagados de debates no saldados o comprendidos. A su vez, los trabajos sobre memoria nos proveen desarrollos específicos sobre la reconstrucción del pasado y la historia de la universidad.Las nuevas interpretaciones y elaboraciones inciden en un espacio en disputa sobre la definición de aquella memoria institucional (Friedemann, 2012). La recuperación de testimonios y documentos nos permiten rastrear en todas ellas cuáles han sido los desafíos y tareas concretas realizadas, y los sentidos que se han otorgado a pequeños y grandes acontecimientos.

Por último, numerosos trabajos se abocan a este estudio definiendo de diversas formas el momento político que transcurre desde finales de la dictadura. Resulta relevante considerar el concepto de refundación, una noción que hemos decidido destacar entre las utilizadas por la bibliografía, ya que consideramos que es la que mejor representa los desafíos de aquel proceso. Algunos de los términos utilizados para caracterizar dicho momento son el de normalización (Perel, Raíces y Perel, 2006; Garatte, 2008) o el de reconstrucción 
universitaria (Buchbinder, 2005), mientras que en otros casos se destaca la idea de modernización en la "universidad de la transición" a la democracia (Rovelli, 2008). Finalmente, se ha sugerido la noción de politica refundacional (Blois, 2009), que resalta la idea de refundación como un proyecto político. Por otro lado, si nos atenemos a las definiciones de los propios actores, también se destaca la impronta (re)fundacional. Para dar un ejemplo, podemos tomar el testimonio de Mario Margulis, ${ }^{7}$ primer director luego de la normalización, quien definió el proceso como "un nuevo comienzo institucional, casi una nueva fundación de la carrera" 8 .

Sumado a esto, partimos de la idea de que el proceso de institucionalización de la Sociología en nuestro país no tuvo un desarrollo lineal. Los acontecimientos y transformaciones producidas mientras transcurría un momento de normalización en la UBA se sucedieron dentro de otro proceso general lleno de marchas y contramarchas. En particular, la noción de refundación nos resulta indicadora de un momento particular en la década del ochenta, caracterizado por la recuperación de la democracia y la reapertura de la carrera de Sociología, lo que nos permite pensar qué se refundó y cómo. En cuanto al concepto de institucionalización, resulta central para poder comprender y situar históricamente una serie de hitos y dinámicas que apuntalan y fortalecen el desarrollo de instituciones y disciplinas. En palabras de Edward Shils (1970, p. 763):

Por institucionalización de una actividad intelectual entiendo la relativa densa interacción de personas quienes conducen dicha actividad (...). El alto grado de institucionalización de una actividad intelectual supone su enseñanza e investigación dentro de la organización regulada, programada y sistemáticamente administrada. La organización regula el acceso a través de un escrutinio de calificaciones y provee juicios organizados de actuación; asigna instalaciones, oportunidades, publicaciones, cargos, etc. También supone la provisión y difusión de los resultados de la actividad más allá de los límites institucionales mediante publicaciones, en el sentido más general de hacer accesibles dichos resultados al público, lego o especializado. ${ }^{9}$

Sin embargo, nuevamente no debe ser entendido este proceso como un avance continuo y unilineal teleológico y por algunos momentos vislumbrado casi como un universal-, lo cual puede deberse a que su contexto de formulación, en pleno "consenso ortodoxo" (Alexander, 1989), es el mismo que el de otros conceptos como modernización o despegue. En contraposición, análisis más recientes han puesto el acento en contextos más amplios (institucionales, económicos, políticos e intelectuales), y en reconocer que las diferentes "sociologías nacionales" atravesaron este proceso en diversas temporalidades y bajo el impacto de distintas circunstancias históricas locales e internacionales (Platt, 2007). En el caso que nos atañe, también debemos resaltar como factor relevante, a partir de los testimonios recolectados, la existencia de redes y vínculos entablados en circunstancias disímiles y muchas veces adversas. Un claro ejemplo, unido al proceso de refundación de la carrera, fue el exilio en México de numerosos académicos, los cuales construyeron redes en el extranjero mientras perfeccionaron sus cualidades profesionales. En ese trayecto, en el relato de Juan Pegoraro, se explica porqué Mario Margulis lo convoca a formar parte del proceso de normalización universitaria por el contacto que habían tenido en México.

$\mathrm{Si}$ atendemos entonces a las particularidades de las historias nacionales de desarrollo disciplinar y situamos estos procesos espacial y temporalmente, podemos configurar un cuadro en el que constantemente se enfrentan dinámicas institucionalizadoras y desinstitucionalizadoras; estas últimas implicarían la "desaparición o el debilitamiento de los activos o recursos necesarios para una mayor institucionalización en términos de empleos profesionales, financiación, revistas, planes de estudio, estima pública o -en regímenes autoritarios- libertad para perseguir el trabajo académico"10 (Fleck, Düller \& Karády, 2019, p. 15). En definitiva, esto permite pensar la construcción de estas instituciones como una instancia dinámica -sin un resultado fijado de antemano-, donde se ponen en juego cuestiones relevantes específicas de cada contexto local, que pueden o no estar en relación con el desenvolvimiento de la sociología a nivel internacional.

Si hacemos explícitas estas cuestiones, podemos considerar que, en el momento en el cual la institución tuvo que reinventarse y reabrir sus puertas, lo hizo retomando la senda abierta en el año 1898 con la creación de la primera cátedra universitaria de sociología local, trayectoria interrumpida con la corta clausura de la carrera y su posterior postergación y aislamiento institucional entre los años 1975 y 1983. Creemos que 
este reinicio puede observarse no solo a través de eventos importantes como la creación de la Facultad, sino, además, a través de una serie de conmemoraciones e hitos dentro y fuera de la institución, que fueron fundantes y contribuyeron con su enriquecimiento. Entre ellos, es posible mencionar la creación del Consejo de Profesionales en Sociología en el año 1988, la Ley no 23.553 del Ejercicio Profesional de la Sociología sancionada el mismo año, la publicación de artículos y libros destacados con motivos de efemérides puntuales, la emergencia de investigaciones y referentes, entre otros sucesos, lo que a su vez refleja "que\# debe ser recuperado, preservado y heredado" como parte de una capacidad institucional que así lo establece (Cardoso, 2016, p. 51).

\section{3- REFundaR, CREAR Y NORMALIZAR}

La culminación de la dictadura en nuestro país en 1983 abrió una nueva etapa plagada de dificultades y reformulaciones políticas y académicas. ${ }^{11}$ En esta coyuntura, Francisco Delich ${ }^{12}$ asumió como rector normalizador de la UBA en diciembre de ese año hasta marzo de 1986. La propuesta política del radicalismo a nivel nacional y la llevada a cabo por el rector se caracterizaron por "cierto ideario ilustrado" que pudiera asegurar la convivencia en la pluralidad de corrientes ideológicas en general y de enfoques disciplinares, materias y docentes en el caso de la universidad (Rovelli, 2008, p. 203). El mismo Delich lo evocaba en un informe escrito para la Facultad Latinoamericana de Ciencias Sociales (FLACSO) en 1987, a poco de abandonar su cargo de rector normalizador: "No se trata de un retorno masivo, pero en cambio altamente calificado. Plural en sus motivaciones, plural en sus orígenes, plural en sus expectativas” (Delich, 2013, p. 118).

Como primera directora de la carrera de Sociología, Susana Torrado ${ }^{13}$ tomó la iniciativa de convocar personalidades que, en algunos casos, habían adherido, en las décadas de 1960 y 1970, a experiencias revolucionarias. Contra "el carácter ajeno de los profesores de la dictadura", Torrado deseaba "atraer a los notables de la sociología local” (Blois, 2009, p. 6). Esto la dirigió a un enfrentamiento con las autoridades nacionales, lo que la obligó a renunciar rápidamente a su cargo. Su sucesor, Cristian Gravenhorst, ${ }^{14}$ llevó a cabo una administración académica en la cual aconteció el primer llamado a concursos sin un plan de estudios definido, sin una línea clara sobre qué especialidades implantar y con condiciones materiales y organizativas deficientes (Blois, 2009). Luego de su renuncia, a mediados de 1986, Mario Margulis asumió la dirección de la carrera con un importante apoyo de las agrupaciones estudiantiles, docentes y graduados, de quienes buscó el consenso necesario durante su gestión al congregar un "órgano consultivo" para mantener allí la idea de pluralidad de enfoques. Tanto él como sus sucesores tuvieron a su cargo la reorganización de la carrera; debieron convocar a numerosos docentes, definir los concursos de materias y buscar los recursos necesarios para tal fin. ${ }^{15}$ Juan Pegoraro, quien había sido secretario académico de Margulis, lo sucedió y asumió como director de la carrera en el mismo año en que se crea la Facultad de Ciencias Sociales (1988), cuyo primer decano sería Juan Carlos Portantiero. ${ }^{16}$

Un hecho fundamental para comprender los cambios y continuidades de la institucionalización de la carrera fue la creación, a través de la Resolución no 2945 del Consejo Superior de la Facultad de Ciencias Sociales de la UBA, del día 7 de septiembre de 1988. La misma integró cinco carreras: Sociología, Comunicación Social, Ciencia Política, Relaciones del Trabajo y Trabajo Social. Los estudios para concretar su creación habían comenzado en 1984 y habían recibido un primer dictamen favorable por parte de una Comisión de Estudio, en función de la creciente importancia de la interdisciplina en la formación académica y el común fundamento epistemológico observado en estas disciplinas. Sin embargo, dificultades políticoinstitucionales -especialmente la transferencia de carreras (y poder) de la Facultad de Filosofía y Letras a la de Ciencias Sociales- demoraron la aprobación de la creación de la nueva casa de estudios. En palabras de Francisco Delich: "la facultad no había sido creada, y las disputas desde luego no son académicas, no tienen relación con orientaciones sino con espacios de poder institucional” (2013, p. 120). 
Entre los objetivos de la Resolución $\mathrm{n}^{\circ} 2.945$ se encontraban: coordinar materias afines, distribuir adecuadamente los recursos, generar una convivencia estrecha entre los alumnos, promover el perfeccionamiento docente, impulsar la relación con otros centros de investigación, entre otros objetivos. Esta misma norma establecía: "es conveniente tender hacia la organización departamental" integrada con una "organización matricial" que preserve la identidad de cada carrera y su articulación interna. Debe comprenderse la importancia de estas propuestas de reformulación académica partiendo de un análisis de la institucionalización de la Sociología en el largo plazo, recordando sus pasos erráticos y las lamentables intervenciones que ha tenido la carrera desde su creación, especialmente en el período 1975-1983. Puntualmente, en esos ocho años, la carrera funcionó dentro de un marco de clara postergación institucional y material, lo cual implicó una breve clausura entre 1975 y 1976, la separación de la unidad académica que la contenía (la Facultad de Filosofía y Letras) y su traslado a espacios aislados e inadecuados como fueron los sótanos de la Facultad de Derecho y Ciencias Sociales (Perel, Raíces y Perel, 2006; Raus, 2007). Por otro lado, la carrera debía integrarse con otras recientemente creadas, ${ }^{17}$ proceso inmerso en las inevitables disputas políticas que genera semejante alteración.

Ya Mario Margulis en una entrevista realizada para el primer boletín de la Facultad en octubre del año 1988 advertía sobre las implicancias de este "proceso de trabajo": "[entre] la Resolución del Consejo Superior y la constitución y puesta en funcionamiento de la Facultad, media un proceso complejo, un proceso de trabajo y organización" (Boletín de Información FCS n ${ }^{\circ}$ ). La tarea significaba unificar cinco centros de enseñanza, repartidos en tres edificios diferentes, cada uno con su personal docente, administrativo, recursos y estudiantes,todos cargando una "cultura institucional" individual. Para Margulis, el primer paso que debía afrontar era la "unificación administrativa", caracterizada por él como una "base material fundamental", la cual afectaba directamente la vida y cotidianeidad de las personas involucradas, y numerosos actos administrativos y responsabilidades.

En el mismo sentido, en el Boletín de Informaciones de la Facultad $n^{\circ} 2$, Miguel Talento ${ }^{18}$ en un reportaje afirmaba la necesidad de comenzar a realizar elecciones y fundar un proceso "democrático y transparente". A su entender, las elecciones eran un instrumento "para avanzar en la construcción colectiva del espacio institucional de las Ciencias Sociales en la UBA”. En aquellas primeras votaciones se elegirían los representantes de cada carrera para el Consejo Académico Consultivo, integrado por dos profesores, un estudiante y un graduado (en el caso de las carreras recientemente creadas, la representación la asumió íntegramente el claustro docente). Además, se designarían los integrantes de las juntas asesoras de carrera. Talento manifestaba que los comicios eran un medio, una "condición necesaria pero no suficiente" en el "proceso de normalización de la Facultad" (Boletín FCS n²).

Dado que dichos documentos entonan un pedido de participación y comunicación destinado a toda la comunidad, nos permiten apreciar aquella voz institucional que intenta analizarse, y recuperar cuáles han sido sus condiciones y desafíos: hacer visible un proceso de reorganización con la necesidad de legitimar las acciones de las autoridades nombradas para su normalización. Luego delas reflexiones realizadas en el apartado anterior sobre las fuentes escogidas, resulta fundamental resaltar que en los primeros boletines de la facultad y de la carrera se enfatiza la trascendencia de la comunicación entre los actores, la democratización de la institución y la importancia asignada a la participación de todos aquellos que forman parte de la comunidad académica. Por citar algún ejemplo, el Boletín de Información n ${ }^{\circ} 1$ de la FCS se presenta como parte de un "esfuerzo para informar, para que todos tengan acceso a la información relevante respecto a la facultad que se está construyendo", como un espacio para que "todos puedan expresarse".

El segundo número del Boletín de informaciones de la Facultad afirmó sus intenciones de instituirse como un canal de comunicación necesario para la "construcción de la nueva Facultad" y la "integración de las carreras que la componen". El mismo documento, propone, a través de un escrito de Christian Ferrer, ${ }^{19}$ la realización de una crónica sobre la historia de la carreras de Comunicación Social y de Sociología. Caracteriza a esta última de "casi centenaria", y construye un relato a partir de una serie de hitos institucionales como son 
la creación de la primera cátedra de Sociología en el país (1898), la creación del Instituto de Sociología y su organización por parte de Ricardo Levene (1941), y, finalmente, la creación de la carrera de grado (1957). Para el autor citado, la "implementación" de esta respondía a una "reorganización profunda del campo intelectual" caracterizado por la inauguración de nuevas carreras, el "desplazamiento de intereses intelectuales hacia un campo de cientificidad que se oponía a las tradiciones especulativas de antaño", la "modernización de los dispositivos universitarios" y el apogeo de "un discurso antitradicionalista y modernizador" sobre la estructura social en el país.

Aquí ubica la figura de Gino Germani, presentado como una "figura controvertida" y el "gestor fundamental -en tanto administrador académico y organizador del paradigma dominante- de la construcción de la sociología durante el período 1955-66". La decisión editorial de describir los orígenes de las carreras de la FCS nos permite observar los esfuerzos por rememorar e instituir una historia institucional y una comunidad académica, construir identidades, y delimitar sus orígenes y tradiciones. Todo esto refleja las dificultades para convocar y legitimar un difícil proceso de creación y unificación de distintas casas de estudio, las cuales contaban con trayectorias, tradiciones y recursos diversos.

A continuación analizaremos qué significaba, según las fuentes escogidas, refundar y normalizar la carrera de Sociología. Tomaremos como primer elemento la realización de los concursos, a través de los cuales se intentaba constituir un plantel docente. En primer lugar, como se ha anunciado más arriba, Susana Torrado y los sociólogos que la acompañaban intentaron evitar que los docentes de la dictadura continuaran dando clases. En segundo lugar, los primeros concursos fueron organizados por áreas, ya que no estaba definido cuáles serían las materias del nuevo plan de estudios. Este no fue el único dispositivo de incorporación de docentes, ya que en numerosas ocasiones fueron convocados de manera informal, por conocimiento entre colegas o por haber formado parte anteriormente de la carrera.

Si bien ciertos mecanismos informales para la incorporación de profesores no son algo exclusivo de esta etapa, las dificultades presupuestarias condicionaron el llamado a concursos y muchos ingresos se realizaron ad honorem. En palabras de Pegoraro: "y hubo muy pocos, hasta que yo estuve, hubo muy pocos concursos. Primero porque no había guita. Porque además no se presentaban, porque claro, eran dedicaciones simples”. Sin embargo, la importancia de los concursos estaba relacionada con la necesidad de establecer autoridades democráticas. En la entrevista realizada a Mario Margulis, con motivo del primer Boletín de Informaciones de la FCS, se hacía referencia a los concursos como parte de un complejo proceso, no solo por la "significación académica” que posee sino porque la definición del claustro docente permitía realizar las elecciones de autoridades fijadas por el Consejo Superior de la UBA para el año 1989, un acto político y organizativo de gran envergadura.

Todo esto involucró la incorporación de docentes que pudieran dar respuesta a la demanda de materias y al crecimiento de la matrícula de la Facultad. De a poco comenzaron a arribar profesionales y propuestas de asignaturas a la carrera, lo que inaugura un fenómeno que nuestros entrevistados calificaron como negativo: el advenimiento de numerosas materias optativas y la consiguiente desarticulación de la formación de los estudiantes (advierten además que esto continúa hasta el día de hoy). Para Cohen y Pegoraro fue el resultado de una política que privilegió una idea amplia de inclusión, lo que podía relacionarse con el empeño de convivencia democrática, aspiración que el radicalismo gobernante tenía para la universidad y la sociedad en general. Juan Pedro Blois (2009) toma en cuenta este punto cuando analiza los concursos como "recurso legítimo" de selección de docentes, y cita al propio Delich para definirlo: "sobre la calidad académica, todos podamos estar, todos podamos convivir" (p. 5). Sumado a esto, la resolución del Consejo Superior de la UBA que instaura el plan de estudios del año 1988 anunciaba como objetivo "proseguir su perfil pluralista" ${ }^{20}$, lo que ratificaba ese espíritu y su proyección institucional.

En el caso de Pegoraro, sostiene que a pesar de que la carrera se fue acrecentando, luego de su gestión funcionó una incorporación "ilógica" de materias optativas. Esto ocurrió en desmedro de una formación troncal fundamental, la cual se encontraba plasmada en el proyecto que, junto con Margulis, intentaron llevar 
a la práctica: "después ocurrió un desbarajuste, porque había demasiadas y hay, ahora, demasiadas optativas; entonces me parece que no hay... digo: ¡los alumnos hoy se pueden recibir sin dar Weber!”. En relación a esto, Pegoraro nos plantea un enriquecido debate en torno a cuáles deberían ser las lecturas obligatorias en la formación de los alumnos; le otorga gran importancia a la conformación de un "perfil científico" a lo largo de la carrera. Por otro lado, sostiene que es necesario asignar contenido a términos que se han vaciado, especialmente el de democracia, instando a fundar una acción política alternativa, la cual llama democraciasocial. En este esfuerzo ubica la labor del sociólogo, advirtiendo cuál era su tarea en el contexto político de los ochenta:

Y bueno se empezó a abrir un abanico, y que los sociólogos éramos importantes. Podían servir. Mucho tiene que ver con el clima político que se vivió con Alfonsín. Ahora tenemos que ver cómo ayudamos a este proceso para que bueno, se consolide democráticamente.

Ahora bien, este nuevo rol inaugurado con la vuelta de la democracia requería cierta formación académica;era un proyecto que evitaba momentos caracterizados como "populistas" y evocaba aquella tradición fundada por Gino Germani:

Me parece que había posibilidades de hacer lo que hicimos. Además, nos interesaba que los alumnos tuvieran una base científica. Cuando digo científica quiero decir que tuvieran horas culo silla. No la charla. No el charlín. Sino que leyeran (...) Le temíamos a la cosa más populista. Para decirlo así, una política que no sea universitaria. Nosotros teníamos un grupo, porque no era yo solo ni Margulis solo, teníamos todo un equipo, la idea de hacer una carrera seria. Que tenía que ver con la tradición de Germani.

En los testimonios aquí recolectados resulta sumamente interesante la descripción que hace Pegoraro sobre los esfuerzos por reorganizar la carrera de Sociología. La mención a Gino Germani, autores como Max Weber y el esquema enunciado de una "base científica" permite entrever cuáles eran las tradiciones sociológicas y las experiencias disciplinares que se valorizaban en aquel momento en el cual debió "refundarse" la carrera de Sociología.

En cuanto a la diagramación concreta del plan de estudios y de la carrera, Néstor Cohen señala que la no diferenciación de la metodología cuantitativa y cualitativa constituye una importante "fortaleza". Sin embargo, disiente con "el criterio" con el cual se incorporaron en aquel momento numerosas materias optativas, generando ciertos problemas que continúan hasta nuestros días:

En ese momento la cosa no se armó bien. Yo soy bastante crítico de Margulis. (...) Nuestra currícula tiene una carencia que es gravísima: no es obligatorio el recorrido sobre lo que es estructura social. Es absolutamente aberrante, yo tengo una posición muy dura tomada en ese sentido, que un sociólogo pueda formarse sin demografía social porque es optativa. Pero me parece aberrante que lo histórico sea un tronco central y lo otro ni secundario. Eso no fue casual, tuvo que ver con una decisión política.

Es por esto que en su testimonio Néstor Cohen relata como rasgo fundamental el hecho de que durante su gestión comenzaran a implementarse las orientaciones de la carrera. El boletín NoticiaS de abril de 1994, bajo el título "A modo de presentación", expone los objetivos de gestión del nuevo director y ofrece un diagnóstico sobre la carrera: "creo no equivocarme si digo que -seguramente en forma involuntaria- hemos permitido que se desdibujara el perfil de nuestra carrera". Frente a esto propone una "mayor racionalidad" en la currícula y convoca a las cátedras y alumnos a colaborar en la definición de "cuál es el perfil y cómo construirlo, cuán pertinente es seguir con esta heterogénea y amplia oferta”. Recomienda para ello un diálogo entre cátedras. Por otro lado, propone que es necesario pensar "qué temáticas sociológicas se están debatiendo en otros lugares del mundo y consideran oportuno incluir en nuestra Carrera".

La superación de la vigencia de dos planes de estudio fue una disputa fundamental en aquel momento, el de 1976 formulado en dictadura y el de 1985 vigente para los alumnos que provenían del Ciclo Básico Común (CBC). En palabras de Pegoraro: "la discusión sobre el plan de estudios fue una discusión fuerte con colegas, porque todos querían poner su especialidad". Resultan interesantes, si tomamos el relevamiento 
realizado por Mancuso (201), las causas por las cuales se crea el plan de estudios del año 1985 (impugnado por los estudiantes) y el propósito que el mismo formulaba de revertir lo instituido por el plan de estudios del año 1976. Entre múltiples falencias, este último abortaba la posibilidad de la pluralidad buscada en la formación, por lo que el nuevo proyecto otorgó al estudiante la opción de conformar un perfil en su formación a través de la selección de materias optativas. Luego de recuperado el perfil pluralista, la consolidación del plan de estudios en 1988 representó la victoria de un consenso y de una regulación fundamental para la carrera, que superó la dificultad de no poder efectivizar los concursos (producto de la incertidumbre que suponía no saber si las materias concursadas formarían parte del plan o no).

Para finalizar, pueden enunciarse diversas herramientas de institucionalización relatadas por Néstor Cohen. En primer lugar, considera de gran importancia que durante su gestión ocurrieron los primeros concursos para auxiliares; en segundo lugar, que se realizaron diversas publicaciones institucionales. Una de ellas fue la revista Nuevo Espacio. En palabras del entrevistado: "usando la editorial que tenía el CBC creamos una revista que era Nuevo Espacio. La sacamos solamente para que pudieran publicar los auxiliares de investigación, porque en ese momento era mucho más difícil publicar". Sus objetivos fueron "estimular la producción intelectual, la crítica", y facilitar "el desarrollo académico, la formación, el debate, el intercambio y la cooperación” ${ }^{21}$. El programa UBA XXII también se profundiza. Creado formalmente en el año 1991 a través de un convenio entre la UBA y el Ministerio de Justicia, había comenzado a dictar clases del CBC en el año 1985 en la cárcel de Devoto. En el año 1987 la carrera de Sociología se suma a este espacio en Devoto, al que luego se incorpora la cárcel de Caseros en 1991 y la cárcel de Ezeiza en 1993 (Daroqui, 2009). En el relato de Cohen se resalta la tarea en equipo realizada con Alcira Daroqui: Cohen hacía las "gestiones políticas" necesarias y Daroqui aportaba sus conocimientos sobre el tema: "cuando yo fui director, abrimos la carrera de Sociología en la cárcel de mujeres, quien me ayuda ahí es Alcira Daroqui”.

A partir de estas disputas y desafíos, que caracterizan un momento analizado por nosotros como refundacional, podemos adentrarnos en las dificultades y oportunidades que la nueva coyuntura de los años noventa presentó para la carrera de Sociología. Reflexionaremos sobre dicho interrogante analizando el contexto de cambios y de reformas políticas y económicas sumado a la descripción del proceso de institucionalización de la carrera.

\section{4- INSTITUCIONALIZAR EN TIEMPOS DE REFORMA NEOLIBERAL}

Las dificultades económicas por las que atravesó el país durante el gobierno radical llegaron a un punto álgido con la crisis hiperinflacionaria de fines de los ochenta. La administración del presupuesto de un sistema universitario que tenía como bandera la gratuidad, el ingreso irrestricto y el cogobierno presentó múltiples dificultades. El personal docente y no-docente veía disminuir su salario real a pasos agigantados y la rápida recuperación del nivel de la matrícula hacia mediados de los ochenta exigía elevados gastos en infraestructura. Por otro lado, las altas casas de estudio comenzaron a formar parte de una nueva agenda estatal que tenía como prioridad controlar la inflación y el déficit fiscal. Para esta agenda, gestionar una "universidad de masas" (Buchbinder, 2005, p. 220) se presentaba como una problemática relevante.

Para el caso de la unidad académica que nos compete, los testimonios recuperados rescatan las dificultades generadas a partir de la creación de la FCS, reuniendo carreras de disímiles tradiciones y orígenes en el tiempo. De qué forma impactó en cada una de ellas es algo pendiente de observación. Sin embargo, si tomamos en cuenta las estadísticas publicadas por el Rectorado de la UBA, podemos describir cómo se desarrolló la demanda para cada una de las carreras, observando la cantidad de ingresantes desde el año 1989 y a lo largo de una década. ${ }^{22}$ Resulta sorprendente el carácter constante que tuvieron dichas cifras al observar las series estadísticas mencionadas: excepto en el año 1990, la carrera de Sociología aportó entre el 17\% y el 21\% de los 
ingresantes cada año, mientras que Comunicación Social se mantuvo entre el 49\% y el 55\% y Ciencia Política entre el 12\% y el 17\% del total de ingresantes (estas dos últimas carreras abiertas a partir del año 1987) ${ }^{23}$.

Iniciada la "era menemista" diversas transformaciones proyectadas o ejecutadas en el sistema de educación superior comprometieron un "proceso de imposición cultural", dirigido desde organismos internacionales como el Banco Mundial (Rubinich, 2001, p. 10). Esto produjo diferentes iniciativas en un contexto en el cual aumentaba la participación de las universidades privadas y la proliferación de maestrías y posgrados producía una importante especialización en las disciplinas. El número de universidades privadas aumentó considerablemente, hasta llegara duplicarse; a su vez,se crearon nuevas universidades estatales (Lanús, General Sarmiento, Tres de Febrero, Quilmes, La Matanza y San Martín) y se crearon o reabrieron carreras de Sociología en otras universidades (La Plata y San Juan). Blois (2017) dirá que esta situación, además de generar oportunidades profesionales para los sociólogos, afectó la "centralidad material y simbólica de la UBA" (p. 251).

La proliferación de estos nuevos espacios, combinada con las dificultades económicas de las "universidades de masas", marcó la aparición de una lógica de pluriempleo: un fenómeno novedoso caracterizado por la doble o triple pertenencia institucional de sus docentes e investigadores (Blois, 2017). A pesar de esto, no necesariamente en esas nuevas universidades estatales se creó la carrera de Sociología, o las carreras creadas en las universidades privadas tuvieron una afluencia sostenida. Consideramos entonces que se produjo en esta década un lento desgaste de la preponderancia de la carrera de Sociología de la UBA frente a nuevas carreras o universidades que ofrecían disciplinas dentro de las Ciencias Sociales (Pereyra, 2017) ${ }^{24}$. Por lo tanto, si bien otras instituciones contaban con nuevas posiciones donde insertarse laboralmente u ofertas de formación de posgrado o más fondos disponibles, la pertenencia a las universidades de prestigio se mantuvo y mantiene a la par que las otras por motivos que consideramos necesario dilucidar. Sin embargo, es destacable el intercambio que se genera por parte de académicos e investigadores en su paso por diversas instituciones, las cuales poseen sus historias y trayectorias, y muchas veces se ven enriquecidas por los contenidos de estos vínculos.

Durante esta década, además de la sanción en 1995 de la Ley n 24.521 de Educación Superior, se crearon diversos organismos, muchos de los cuales continúan vigentes hasta el día de hoy: el Consejo Interuniversitario Nacional (CIN), la Secretaría de Políticas Universitarias (SPU), la fundación de la Comisión Nacional de Evaluación y Acreditación Universitaria (CONEAU), el establecimiento del Sistema de Información Universitaria (SIU), un Fondo para el mejoramiento de la calidad universitaria (FOMEC), el Consejo de Universidades (CU), un programa de incentivos para los docentes e investigadores que a su vez implicaba un sistema de categorización de los mismos, entre otras iniciativas. Todo esto inaugura nuevos parámetros basados en nociones como calidad y evaluación, y en un incremento de medidas tendientes a aumentar el control sobre la universidad para regularla directa o indirectamente (Naidorf, 2009). A su vez, la diferenciación y especialización del campo académico se profundizará en un contexto caracterizado por la reestructuración del sistema universitario como parte integrante de un proceso de reforma estructural del Estado (Rinesi, Soprano y Suasnábar, 2005).

La actividad de ciencia y tecnología durante la dictadura había tenido un difícil desarrollo. Debió soportar la selección de las temáticas preferenciales para el gobierno de facto, y luego enfrentarse con la falta de recursos económicos a fines de los ochenta y durante la década siguiente. Es por eso que diversas iniciativas en la década del noventa se encaminaron a reparar esta situación. Un ejemplo fue la creación de la Agencia Nacional de Promoción Científica y Tecnológica a fines del año 1996 mediante el Decreto $n^{\circ}$ 1.660/96, que inició su actividad el 20 de mayo de $1997 .{ }^{25}$ El mismo decreto que establecía el programa de incentivos nombrado más arriba denunciaba entre sus fundamentos la necesidad de promover el desarrollo de la docencia junto con la investigación, extensión y gestión, y detallaba que "de una planta global de docentes del sistema de Universidades Nacionales del orden de los cien mil (100.000) cargos, menos de quince por ciento (15\%) participa en actividades de investigación científica y tecnológica" ${ }^{26}$. Esta disparidad y falta de oportunidades 
profesionales se observará más adelante en una de las publicaciones de la carrera de Sociología seleccionadas para el presente trabajo.

En el ámbito de la UBA, para dar cuenta de un legado que se venía construyendo en las diferentes iniciativas y relatos alrededor de la refundación de la carrera, podemos mencionar el cambio de nombre acaecido sobre el Instituto de Investigación de la carrera de Sociología. El mismo pasó a albergar a todas las carreras que formaron parte de la FCS a partir del año 1988 con la denominación de Instituto de Investigaciones de la Facultad de Ciencias Sociales, y fue rebautizado en 1992 con el nombre Instituto de Investigaciones Gino Germani (IIGG). Aquí queremos destacar la escasez de trabajos que reconstruyen este momento, que logra pasar desapercibido en los análisis sobre la historia institucional y sobre los legados del sociólogo romano. Reconocemos, junto con Cardoso (2016), que existió un "recupero institucional de la figura fundante de Germani” (p. 44), el cual se puede avizorar a través de diferentes acontecimientos o publicaciones. Por citar algunos: en 1991 se publicó en el Boletín de Informaciones de la Facultad y en la revista Ciencia Hoy una semblanza escrita por Norma Giarraca, en donde se celebraban los 80 años del natalicio de Germani y se revalorizaba su figura; en 1992 se editó un libro en homenaje al $35^{\circ}$ aniversario de la publicación de Estructura Social de la Argentina, dirigido por Jorge Raúl Jorrat y Ruth Sautu, llamado Despue\#s de Germani. Exploraciones sobre la Estructura Social de la Argentina; en 1997 se publicó un artículo de Enrique Oteiza ${ }^{27}$ sobre la labor de Germani en la revista de CLACSO con motivo de su 30 aniversario; en el mismo año se publicó un libro escrito por Darío Canton y Jorge Jorrat llamado La investigación social hoy: a 40 años de la creación del Instituto de Sociología. Aunque excede los objetivos del presente trabajo, consideramos que el cambio de nombre ocurrido en el Instituto de Investigaciones de la facultad es la síntesis de un esfuerzo por revalorizar una figura junto a imaginarios asociados a un momento fundante de la disciplina en nuestro país.

$\mathrm{Al}$ igual que los relatos recuperados en el apartado anterior, la figura de Germani se convocó como un legado que habilitaba cierta herencia académica, la cual se vinculaba con una tradición de la disciplina considerada legítima. Sumado a esto,como se ha enumerado brevemente en la introducción, en la década del noventa el proceso de institucionalización y profesionalización de la Sociología como disciplina alcanza cierta consolidación con la sanción, en el año 1988, de la Ley nº 23.553 de Ejercicio Profesional de la Sociología, y la creación del Consejo de Profesionales de Sociología.

Luego de esta breve reseña, en la que examinamos cuáles han sido las tareas y desafíos presentes en la década del ochenta como parte del proceso de refundación y normalización, intentaremos describir de qué forma la crisis acontecida en el país y en la universidad tomó sitio en la carrera de Sociología y en la recientemente creada FCS. Es decir que, para seguir con los objetivos planteados para el presente trabajo, intentaremos exponer de qué modo las fuentes manifiestan esta reforma estructural.

En cuanto a los boletines de la Facultad, el número dos presenta un juicio contundente.El mismo expresa que esta fue una "etapa caracterizada por grandes acontecimientos políticos y sociales y por una terrible crisis económica" (Boletín $n^{\circ} 2$, nov-dic 1988). La característica de la falta de recursos es destacada en las entrevistas realizadas como el obstáculo principal a todo aquello que se propusieron en sus gestiones como directores de la carrera. Esto se corrobora en los documentos institucionales, como por ejemplo en el Boletín NoticiaS de agosto de $1994,{ }^{28} \mathrm{el}$ cual anuncia el llamado a concurso para profesores titulares y adjuntos para "aquellos que habían cumplido ya los 7 años establecidos como vigentes", y además advierte que "próximamente continuará el proceso iniciado en 1988 y demorado en el Consejo Superior de la UBA".

En el mismo boletín, bajo el título "Recursos escasos" la dirección de la carrera denuncia que la Secretaria Académica de la Facultad tiene un interés en realizar los concursos pero también en la necesidad de "reducir la cantidad de «puntos docentes» (léase salarios docentes)" consecuencia de "la escasez de recursos económicos de esta Facultad". En respuesta a esta situación, la Dirección de la carrera expresaba en el boletín que no estaba dispuesta a realizar reducciones de este tipo. Pero terminaba reconociendo que a causa de esta carencia es necesario llevar a cabo diversos mecanismos, como redistribuir tareas, compartir recursos entre cátedras afines o dictar un cuatrimestre al año materias con pocas inscripciones. 
El dossier publicado por la Dirección de la carrera de Sociología en mayo de 1999 presentaba un apartado dedicado a la "situación de los concursos", en el que se publicaba en porcentajes la condición de la población de docentes rentados. De este grupo, únicamente el 37,5\% de los profesores se encontraban en condición de regulares;este porcentaje disminuye de forma alarmante, al 2,2\%, para el caso de los auxiliares. A pesar de que todas las materias del tronco común estaban llamadas a concurso, estos se encontraban frenados, sin formación de jurado, habían caducado o se hallaban a la espera de aprobación del jurado por el Consejo Superior.

El dossier citado iniciaba su publicación afirmando de manera contundente: "La crisis universitaria de fin de siglo tiene en el desfinanciamiento de la actividad una de sus principales causas". Doce años después de la creación de la Facultad de Ciencias Sociales, dicha carrera emitió un documento destinado a toda su comunidad para dar a conocer los detalles de la situación y plantear un "debate serio y profundo". Se afirmaba que la escasez presupuestaria se veía manifestada en una "biblioteca deficiente y desactualizada", en condiciones edilicias y espaciales en general "paupérrimas", y en la falta de recursos tecnológicos. Sin embargo, la situación no se expresaba únicamente allí, la alarma estaba puesta en las condiciones salariales docentes. En el documento se llega a afirmar que Sociales constituye una facultad sostenida por "una gran dosis de voluntarismo", sin la cual no podría funcionar.

En la introducción del documento se explicitan los tipos de categorías docentes (asociadas en dos grupos: profesores y auxiliares), los cargos y dedicaciones, y las posibles combinaciones de todos ellos. A su vez, contrapone los cargos adhonorem de los rentados y los docentes regulares (concursados) e interinos. El cuadro presentado que se forma de las combinaciones de todas las categorías arriba expuestas arroja saldos sumamente llamativos. Algunas páginas después, el dossier concluye que el $67 \%$ de los profesores de Sociología se encuentran percibiendo una renta, mientras que este porcentaje desciende al $50 \%$ para el caso de los auxiliares. Por lo tanto, el $44 \%$ de todo el plantel docente se encontraba trabajando en condición adhonorem, y la dirección de la carrera afirmaba que esto implicaba un "subsidio" importantísimo para la universidad, la cual, además, se encuentra in crescendo.

De la misma manera se pronuncian los informes de gestión de la FCS. Los mismos contienen ciertas resoluciones que anuncian cómo se encontraba movilizada la comunidad académica por la afectación de recursos en la convocatoria docente. Así, el Informe del año 1992 declara en su Resolución (CD) n 673/92 que "rechaza la resolución (CS) no 2.318/92 acerca de las limitaciones a las designaciones docentes". Del mismo modo, la Resolución (CD) n 880/92 "adhiere a la convocatoria realizada por la Gremial Docente y el CECSo para participar de la reunión de Consejo Superior del día 28 de octubre de 1992 donde se tratará la resolución (CS) n 2.318/92”.

El informe de gestión del año 1994 posee dos resoluciones en relación al área de investigación y posgrado, y a su organización administrativo-académica, que revelan la carencia de recursos tanto en relación a las becas como a los "fondos necesarios" para tal área. De este modo, la Resolución (CD) nº 16/94 solicita "informes al Instituto de Investigaciones y a la Secretaría de Ciencia y Técnica de la UBA acerca de la reducción de la oferta de becas" y la no 275/94 encomienda a la Secretaría de Posgrado que "arbitre los medios necesarios para la captación de fondos necesarios para la Maestría en Investigación en Ciencias Sociales”.

A partir de estas fuentes podemos acercarnos a un proceso vivido por la FCS, que demuestra la permeabilidad entre la realidad vivida en el interior de sus cuatro paredes, y las condiciones por las que atravesaba todo el sistema universitario y el país en general. Se ha intentado reconstruir cómo esta situación se involucró con un proceso de reconstrucción universitaria iniciado luego de la recuperación de la democracia en Argentina. 


\section{5- Conclusiones}

Nos hemos propuesto en este artículo presentar una serie de elementos que nos permitan realizar una reconstrucción histórica de un momento transitado por la carrera de Sociología de la UBA luego de su refundación en la década del ochenta y dentro de un proceso de normalización planificado para toda la Universidad de Buenos Aires. A su vez, unir esta coyuntura a la que se inicia en los años noventa ofrece una imagen que resalta las particularidades de cada momento, pero también la similitudes y continuidades que se establecen entre ambos períodos. Tanto la efervescencia de la reapertura democrática de 1984 como la serie de reformas neoliberales que afectan a la universidad en la década de 1990 acompañan un tortuoso camino en el que la carrera se refunda, luego del oscuro proceso que atravesó durante los años de la dictadura (1976-1983). La carrera estuvo tensionada por varios factores, como la necesidad de armar un nuevo plan de estudios, su inclusión en una novel unidad académica, y la falta de recursos materiales; es por ello nuestro estudio se inserta dentro de un análisis sobre la institucionalización de la Sociología en nuestro país, entendiéndolo como un proceso para nada lineal, lleno de avances y retrocesos. Señalamos que el objetivo no ha sido meramente enumerar acontecimientos sino analizarlos en su complejidad y en el contexto político y económico por el cual atravesaba nuestro país en aquella difícil coyuntura. Por este motivo es que hemos vinculado hechos y publicaciones tanto en la década del ochenta como del noventa, sin presionar los relatos en una periodización inmersa solamente en la vida de la universidad, o que responda únicamente al contexto nacional.

En aquel momento, la creación de nuevas carreras en la FCS se suma a una proliferación en la oferta de posgrados, nuevas universidades públicas y privadas, lo que produce una especialización y diferenciación de los títulos. Sin embargo, creemos que este hecho no legitima necesariamente la tesis que sostiene la pérdida de prestigio de la UBA. A pesar de que el sondeo de una situación como aquella requiere un estudio específico y minucioso, podemos observar que se produjo un fenómeno de doble o triple pertenencia institucional: por motivos un tanto complejos, a la par que se accedía a nuevos trabajos y espacios académicos en otras universidades, se mantenía y mantuvo la pertenencia a ciertas universidades, cuyo prestigio proviene de otras fuentes. A su vez, estas redes produjeron y producen todavía hoy diversos intercambios que enriquecen la labor académica en las altas casas de estudio.

La importancia asignada a los boletines de la carrera y de la FCS, como medios de difusión y convocatoria destinada a toda la comunidad, se propone dar voz a los labores, intentos políticos y desafíos en un complicado trabajo de unificación de cinco carreras en esta nueva casa de estudio. De su lectura y análisis emerge de forma preponderante la cuestión de la recuperación del ideario "modernizador" de la fundación original de la carrera en 1957,así como el marcado énfasis puesto sobre el pluralismo ideológico. Ambos factores entran en contradicción; a pesar de que aquel pluralismo es enunciado como una fortaleza ideológica y académica, cuando se traduce en numerosas materias optativas se vuelve una circunstancia negativa para la formación tal como es evaluada por los directores de carrera de aquel entonces que hemos entrevistado. Resta observar en futuras indagaciones si esta diversidad mencionada por la literatura pudo ser traducida en una pluralidad y apertura política a la hora de gobernar, administrar y representar al conjunto del espacio académico de la facultad.

Sumado a esto, en los relatos recopilados, la enunciación de la experiencia germaniana se recupera como hito fundante y legitimador de una historia institucional de la disciplina. En el contenido de estas construcciones identitarias radica el interés del presente trabajo, ya que entendemos que aquellos imaginarios construidos y sostenidos alrededor de la obra de Germani forman parte de una revalorización efectuada y transmitida a través de publicaciones, eventos, conmemoraciones, prácticas académicas y políticas, entre múltiples formas. No resulta casual que este ejercicio se realizara en un momento en el cual la carrera de Sociología de la UBA reabrió sus puertas, para refundarse y convocar nuevamente a sus egresados, muchos en el exilio, luego del difícil proceso acontecido durante la dictadura. A su vez, no podíamos abstraer esta labor de una dimensión mayor: la creación de la Facultad de Ciencias Sociales. Es por eso que entendemos 
la reapertura de la carrera de Sociología como una refundación, como una tarea relevante por reinstituir una disciplina, emparentándola con una trayectoria previa que se decide revalorizar y rescatar en un escenario preciso. Aquí la institución, tal como la entendemos, es algo que debía erigirse, construirse, nombrarse y llenarse de contenido, definiendo su identidad en relación a otros escenarios, sujetos, imaginarios o carreras.

Por otro lado, la peculiaridad de los testimonios característicos de la década del noventa enuncia los obstáculos materiales e institucionales con los cuales las autoridades se enfrentaron a la hora de normalizar y asegurar el funcionamiento de la carrera. Haber podido confrontar testimonios actuales de quienes han sido directores de carrera con aquellos relatos institucionales publicados en el momento de la refundación nos permitió problematizar un relato histórico imbricado con el análisis de la historia reciente y con la historia de la universidad en nuestro país. Esto fue una decisión metodológica que buscó enriquecer el debate histórico y no trasladar hechos y eventos al presente tal como fueron contados en aquel entonces. Sobre todo se priorizó la diversidad de las fuentes a la hora de intentar describir imaginarios y sentidos otorgados a un nuevo comienzo institucional.

Creemos que estos matices propios de los testimonios y documentos caracterizan un proceso de forma compleja, mostrando las posibilidades reales, los factores contingentes y las confrontaciones de proyectos políticos diversos, y nos permiten abordarlos como puntapié para potenciar debates actuales. Consideramos que es posible y queda pendiente rastrear otras voces aquí no contempladas, y además profundizar, en posteriores indagaciones, cómo ha afectado a la vida institucional y a la comunidad académica el proceso político y económico seleccionado, sobre todo si consideramos las consecuencias de las políticas del gobierno nacional en materia de educación, ciencia y tecnología. Por último, señalamos que el año 2018, luego de haber cumplido sesenta años la carrera de Sociología, nos encuentra presenciando conversatorios que debaten la reforma del plan de estudios de 1988. Qué lecturas, tradiciones y referentes intelectuales se recuperan a la hora de reelaborar el mismo tiene mucho que ver con el momento político analizado. Es por eso que el concepto de refundación forma parte de esta propuesta, la cual entiende que las rupturas epistemológicas, las revisiones teóricas y las derrotas políticas fueron y son constitutivas del camino de institucionalización de la sociología en nuestra universidad.

\section{REFERENCIAS}

Alexander,J.C. (1990). Lasteorías sociológicas desde la Segunda Guerra Mundial. Análisis multidimensional. Barcelona: Gedisa Editorial.

Alfredo, M. A. (2014). Intelectuales y expertos en la transición democrática argentina. Los casos de los sociólogos Juan Carlos Portantiero y Juan Carlos Torre (1983-1989). Actas de las VIII Jornadas de Sociología de la UNLP, Argentina. Recuperado de: http://www.memoria.fahce.unlp.edu.ar/trab_eventos/ev.4282/ev.4282.pdf

Baldoni, M. (2008). Intelectuales, sociología y democracia. La perspectiva democrática de Juan Carlos Portantiero y Emilio De Ipola durante los años ochenta. Actas de las V Jornadas de Sociología de la UNLP, Argentina. Recuperado de: http://www.memoria.fahce.unlp.edu.ar/trab_eventos/ev.5866/ev.5866.pdf

Beltrán, G. (2005). Formación profesional y producción intelectual en tiempos de cambio político. En B.Levy y P. Gentili (Comps.), Espacio público y privatización del conocimiento (pp. 463-521). Buenos Aires: CLACSO.

Bizai, J., Harracá, M., y Stechina, M. (2010). La inserción de los sociólogos en el espacio universitario. En L. Rubinich yG. J. Beltrán, (Eds.) ¿Qué hacen los sociólogos? (pp. 73-95). Buenos Aires: Aurelia Rivera.

Blanco, A. (2006). Razón y modernidad. Gino Germani y la sociología en la Argentina. Buenos Aires: Siglo XXI Editores.

Blois, J. P. (2009). Sociología y democracia: la refundación de la carrera de Sociología en la Universidad de Buenos Aires (1984-1990). Sociohistórica. Cuadernos del CISH, 26, 111-150. Recuperado de: http://sedici.unlp.edu.ar/ handle/10915/13755 
Blois, J. P. (2014). El mercado de trabajo de los sociólogos en Argentina desde la vuelta de la democracia. El caso de los graduados de la UBA. Trabajo y Sociedad, 22, 103-122. Recuperado de: https://ri.conicet.gov.ar/ handle/11336/34224

Blois, J. P. (2017). Medio siglo de sociología en la Argentina. Ciencia, profesión y politica (1957-2007). Buenos Aires: EUDEBA.

Buchbinder, P. (2005). Historia de las universidades argentinas. Buenos Aires: Editorial Sudamericana.

Caimari, L. (2017). La vida en el archivo. Goces, tedios y desvios en el oficio de la historia. Buenos Aires: Siglo XXI Editores.

Cardoso, M. N. (2016). Memoria histórica y prácticas discursivas en el espacio conmemorativo Estudio del $50^{\circ}$ aniversario de la carrera de Sociología en la Universidad de Buenos Aires en el 2007. Universidad Nacional de San Martín, Instituto de Altos Estudios Sociales, Ciudad Autónoma de Buenos Aires, Argentina.

Casco, J. M. (2007). Juan Carlos Portantiero: la persistente vocación intelectual de la sociología Argentina. Nómadas, 27, 197-207. Recuperado de: https://www.redalyc.org/html/1051/105116595015/

Casco, J. M. (2008). El exilio intelectual en México. Notas sobre la experiencia argentina 1974-1983. Apuntes de investigación del CECYP, 13, 149-164. Recuperado de: http://www.apuntescecyp.com.ar/index.php/apuntes/ article/view/273/241

Daroqui, A. (Comp.) (2009). Veinte años de la Carrera de Sociología en el programa UBA XXII. Universidad en las cárceles. Buenos Aires: Facultad de Ciencias Sociales - UBA.

Delich, F. (2013). Memoria de la Sociología Argentina. Córdoba: Alción Editora.

Fleck, C., Düller, M. \& Karády, V. (2019). Introduction: Shaping Disciplines-Recent Institutional Developments in the Social Sciences and Humanities in Europe and Beyond. En C.Fleck, M.Düller \& V. Karády (Eds.), Shaping Human Science Disciplines. Institutional Developments in Europe and Beyond (pp. 1-24). London \& New York: Palgrave Macmillan.

Freiburn, N. (2014). La reinvención de la democracia. Intelectuales e ideas políticas en la Argentina de los ochenta. Buenos Aires: Ediciones Imago Mundi.

Garategaray, M. (2018). Unidos. La revista peronista de los ochenta. Bernal: Universidad Nacional de Quilmes Editorial.

Friedemann, S. M. (2012). Aportes del campo de estudios sobre memoria para un abordaje reflexivo del pasado reciente universitario. Aletheia, 2(4), 1-9.Recuperado de: http://www.memoria.fahce.unlp.edu.ar/art_revistas/pr.5291/ pr.5291.pdf

González, H. (Comp.) (2000). Historia crítica de la Sociología argentina. Los raros, los clásicos, los cientificos, los discrepantes. Buenos Aires: Ediciones Colihue.

Lesgart, C. (2003). Usos de la transición a la democracia: ensayo, ciencia y política en la década del '80. Rosario: Homo Sapiens.

Mancuso, M. (2011). La Carrera de Sociología de la UBA, su currícula a través de los años. 1958-2011. Actas de las IX Jornadas de Sociología, Argentina. Recuperado de: http://archivosociologia.sociales.uba.ar/wp-content/ uploads/sites/34/2015/10/06-Doc-PlanesEstSocio-MaraMANCUSO.pdf

Naidorf, J. (2009). Los cambios en la cultura académica de la universidad pública. Buenos Aires: Eudeba.

Noé, A. (2005). Utopia y desencanto. Creación e institucionalización de la Carrera de Sociología de la Universidad de Buenos Aires: 1955-1966. Buenos Aires: Miño y Dávila Editores.

Perel, P., Raíces, E., y Perel, M. (2006). Universidad y dictadura. Derecho, entre la liberación y el orden (1973/83). Buenos Aires: Ediciones del CCC.

Pereyra, D. (2007). Cincuenta años de la Carrera de Sociología de la UBA. Algunas notas contra-celebratorias para repensar la historia de la Sociología en la Argentina. Revista Argentina de Sociología, 5(9), 153-159. Recuperado de: http://www.scielo.org.ar/pdf/ras/v5n9/v5n9a10.pdf

Pereyra, D. (2010). Los científicos sociales como empresarios académicos. El caso de Gino Germani. En D. Pereyra (Comp.), El desarrollo de las ciencias sociales. Tradiciones, actores e instituciones en Argentina, Chile, México y Centroamérica (pp. 35-54). San José de Costa Rica: Cuadernos de Ciencias Sociales - FLACSO. 
Pereyra, D. (2017). Notas sobre la crisis de la sociología argentina. Formación y desarrollo profesional en cuestión. Entramados y Perspectivas. Revista de la Carrera de Sociologia, 7(7), 96-129.

Platt, J. (2007). Some Issues in Comparative, Macro and International Work in the History of Sociology. The American Sociologist, 38(4), 352-363.

Raus, D. (2007). La sociología en el Proceso. Sociología en Debate, 1(1), 35-48.

Rinesi, E. (2000). La historia sin red. En H. González (Comp.), Historia crítica de la Sociología argentina. Los raros, los clásicos, los cientificos, los discrepantes (pp. 519-530). Buenos Aires: Ediciones Colihue.

Rinesi, E., Soprano, G., y Suasnábar, C. (2005). Universidad: reformas y desafios. Dilemas de la educación superior en la Argentina y el Brasil. Buenos Aires: Prometeo Libros-Universidad Nacional de General Sarmiento.

Rovelli, L. I. (2008). La impronta modernizadora y los sedimentos de la Ilustración. Un estudio del conflicto de proyectos en la Universidad de Buenos Aires durante los años 80 y 90. En F.Naishtat, P. Aronson (Eds.), Genealogía de la universidad contemporánea (pp. 201-220). Buenos Aires: Biblos Sociedad.

Rubinich, L. (1999). Los sociólogos intelectuales: cuatro notas sobre la sociología en los años 1960. Apuntes de Investigación del CECYP, III(4), 31-55.

Rubinich, L. (2001). La conformación de un clima cultural. Neoliberalismo y universidad. Buenos Aires: Libros del Rojas-Universidad de Buenos Aires.

Rubinich, L., y Beltrán, G. J. (Eds.) (2010). ¿Qué hacen los sociólogos?. Buenos Aires: Aurelia Rivera.

Shils, E. (1970). Tradition, Ecology and Institution in the History of Sociology. Daedalus, 99(4), 760-825.

Sidicaro, R. (1993). Reflexiones sobre la accidentada trayectoria de la sociología en la Argentina. Cuadernos Hispanoamericanos, 517-9, 65-76.

Vezzetti, H. (2018). Los problemas de la democracia: Guillermo O’Donnell y Juan Carlos Portantiero. En C.Altamirano y A.Gorelik, (Eds.), La Argentina como problema. Temas, visiones y pasiones del siglo XX (pp. 347-358). Buenos Aires: Siglo XXI Editores.

\section{Notas}

1 Nuestro escrito se enmarca dentro de las investigaciones llevadas adelante en el proyecto UBACyT Atención, sociólogos trabajando. Desafios de la profesionalización de la sociología en argentina entre 1961 y 1990 (Código 20020150100039BA) dirigido por el Dr. Diego Pereyra. Además queremos agradecer a nuestros compañeros del Grupo de Estudio en Historia y Enseñanza de la Sociología (GEHES-HSSA) y del Grupo de Lectura Entre Pares, ambos con sede en el Instituto Gino Germani, por haber leído versiones previas del escrito y por sus valiosos comentarios, que sin duda alguna fueron un aporte fundamental para la realización de este trabajo.

2 Forma parte de los móviles que han impulsado el presente trabajo la vigencia que mantiene el proceso seleccionado, con atencióna sus repercusiones actuales: la necesidad de reformar el plan de estudios sancionado en aquellos años. Actualmente la carrera de Sociología de la UBA atraviesa un proceso de consulta para realizarla, para más información sobre estas actividades ver: http://sociologia.sociales.uba.ar/ref-plan-de-estudio/

3 Entrevistas realizadas por la Dirección de la carrera de Sociología con motivo de las XII Jornadas de Sociología (2017) a 60 años de la creación de la carrera: https://www.facebook.com/saved/?cref=28.

4 Juan Pegoraro nació en Rosario, provincia de Santa Fe. Se recibió de abogado en la Universidad Nacional del Litoral y ejerció dicha profesión durante 14 años, a la par que transitaba experiencias académicas, docentes y "literarias". Su rol en la defensa de presos políticos lo obligó a exiliarse en México, país en el cual realizó una maestría en Ciencias Sociales becado por la Facultad Latinoamericana de Ciencias Sociales (FLACSO) y ejerció la docencia en casas de estudio como la Universidad Autónoma Metropolitana (UAM) y también actividades de investigación sobre temas relacionados a la teori\#a del Estado, criminología y delitos económicos. Allí conoció a Mario Margulis, quien lo convocó a formar parte de la refundación de la carrera de Sociología de la UBA. Antes de ser director de la carrera Pegoraro ocupó el cargo de secretario académico durante la gestión de Mario Margulis (Entrevista realizada por Cecilia Civallero a Juan Pegoraro en marzo del 2016).

5 Néstor Cohen nació en Capital Federal, hijo de una familia de comerciantes de tendencia socialista, asistió al Colegio Nacional de Buenos Aires y, según su testimonio, sus inquietudes sociales lo llevaron a estudiar Sociología. Luego de su graduación comenzó a trabajar como asistente de Manuel Mora y Araujo para iniciarun fructuoso camino de formación en Metodología de la Investigacio\#n. Durante la dictadura abandonó un tiempo Buenos Aires y al volver 
se dedicó a la investigación de mercado. Por aquellos años, al finalizar la dictadura, trabajó en diversos centros de investigacio\#n a la par que se reincorporaba al mundo académico. A Cohen lo convocan aquellas personalidades que habi\#an trabajado con él en instituciones académicas como Fundacio\#n Bariloche, Centro de Estudios Urbanos y Regionales (CEUR), Centro de Estudios de Población (CENEP) y Centro Interamericano de Desarrollo Social (CIDES-OEA), además de otras redes que atravesaban espacios como el Colegio de Graduados de Sociología (Entrevista realizada por Cecilia Civallero a Néstor Cohen en abril del 2017).

6 Las dos iniciativas a las que nos referimos son el Archivo Histórico de la Carrera de Sociogía (http://archivosociologi a.sociales.uba.ar/) y el Archivo Historia de la Sociología en Argentina (http://iigg.sociales.uba.ar/archivo-historia-de-1 a-sociologia-en-argentina/).

7 Mario Margulis nació en el año 1932, estudió Sociología en la Universidad de Buenos Aires, en la cual se desarrolló como docente e investigador a mediados de la década de 1960. Sus estudios se centran en la sociología de la cultura. Fue el primer decano organizador de la Facultad de Ciencias Sociales en el año 1988, luego de su exilio en México durante la última dictadura militar en Argentina.

8 Entrevista realizada a Mario Margulis en Rinesi (2000).

9 Traducción propia

10 Traducción propia

11 A mediados de los años setenta la carrera de Sociología y Psicología fueron separadas de la Facultad de Filosofía y Letras por considerarse depositarias de elementos marxistas y subversivos. Luego de una breve interrupción de la carrera (en los años 1975 y 1976), Sociología pasa a depender del Rectorado; dicta sus clases en el edificio del Hospital de Clínicas y en el Colegio Nacional de Buenos Aires, y finalmente es transferida a la Facultad de Derecho y Ciencias Sociales. Durante la dictadura funcionó en las llamadas "catacumbas", en el subsuelo de la facultad antes mencionada. Se censuraba violentamente y limitaba el dictado de materias o temáticas que no tuvieran que ver con los objetivos del proyecto científico y militar del gobierno de facto (Perel, Raíces y Perel, 2006).

12 Francisco Delich nació en Córdoba en 1937, allí se doctoró en Derecho y Ciencias Sociales. Fue profesor y rector en la Universidad de Córdoba y de Buenos Aires, secretario ejecutivo del Consejo Latinoamericano de Ciencias Sociales (CLACSO) entre 1976 y 1983, convencional constituyente por la Unión Cívica Radical (UCR) en 1994, senador provincial en 1997 y diputado nacional entre 2005 y 2009. Ha escrito varios libros, dirigido centros de investigación, y fue director de la Biblioteca Nacional entre 1999 y 2001.

13 Susana Torrado es doctora por la Universidad de París, fue una de las primeras egresadas de la carrera de Sociología de la UBA, discípula de Gino Germani. Docente e investigadora en instituciones como FLACSO (Facultad Latinoamericana de Ciencias Sociales), CLACSO, IDES (Instituto de Desarrollo Económico y Social), CELADE (Centro Latinoamericano de Demografía), CEUR (Centro de Estudios Urbanos y Rurales) y CONICET (Consejo Nacional de Investigaciones Científicas y Técnicas). Al igual que Delich, su participación en la UCR la vinculó al proceso iniciado con Raúl Alfonsín en 1983.

14 Los pocos datos que podemos citar de la trayectoria de Cristian Gravenhorst son los siguientes: graduado de la carrera de Sociología de la UBA en 1976,se desempeñó entre 1972 y 1975 como asistente de dirección en el marco del Proyecto Modelo Mundial Latinoamericano de la Fundación Bariloche. Con posterioridad, comenzó a trabajar en CLACSO, donde conoció y se convirtió en colaborador de Francisco Delich. Este vínculo fue una de las razones por las cuales Delich (en su rol de rector normalizador de la UBA) decidió nombrarlo su delegado en la carrera de Sociología en reemplazo de Susana Torrado (Blois, 2009).

15 Puntualmente, sobre el proceso de recambio de autoridades y concursos ver Blois (2009 y 2017).

16 Juan Carlos Portantiero nació en Buenos Aires en el año 1934, estudió Sociología en la Universidad de Buenos Aires. Sus estudios se han centrado en el marxismo, las nuevas izquierdas, el orden político y las democracias, entre otros. Participó, como fundador, de las revistas Pasado y Presente, Controversia y La Ciudad Futura. A partir de 1983, se convirtió en asesor del gobierno radical de Raúl Alfonsín (1983-1989) en Argentina. Fue decano de la Facultad de Ciencias Sociales por dos períodos consecutivos (1990-1998) y profesor titular a cargo de la materia Sociología Sistemática de la carrera de Sociología de esa facultad. Falleció en 2007.

17 Esto atañe particularmente a Ciencia Política y Comunicación Social, que nunca antes habían sido dictadas como carreras en la Universidad de Buenos Aires. Ambas comenzaron a organizarse en el año 1984-85, y abrieron su oferta de cursos en el año 1987. En cambio, Trabajo Social había dependido de la Facultad de Derecho y Ciencias Sociales (FDCS) desde 1946 y tenía la denominación de -a partir de 1974- Escuela de Servicio Social. Por último, Relaciones del Trabajo había sido creada en 1978, también bajo la órbita de la FDCS.

18 Miguel Talento es abogado y procurador de la UBA. Es profesor titular de dicha universidad, de la Universidad Nacional de Lomas de Zamora (UNLZ) y del Instituto Universitario Nacional del Arte (IUNA). Ha sido director y codirector de proyectos de investigación UBACyT. Fue presidente de la Comisión Nacional de Evaluación y Acreditación Universitaria (CONEAU) en el período 2004-2008, legislador de la Ciudad de Buenos Aires (2003-2007), y embajador a cargo del Consulado de Miami en Estados Unidos de América (2008-2015). 
19 Christian Ferrer es sociólogo y doctor en Ciencias Sociales por la UBA, fue titular de materias de grado y posgrado, de proyectos de investigación, y se desempeñó también como director de la carrera de Comunicación Social en dicha universidad. Ha escrito numerosos libros y ensayos vinculados al estudio de la técnica, las sociedades de control, la libertad, el anarquismo, entre otros.

20 Resolución n 2.282 del Consejo Superior de la Universidad de Buenos Aires, 2 de marzo de 1988. Archivo Histórico de la Carrera de Sociología, Facultad de Ciencias Sociales, UBA.

21 Documento institucional de la Dirección de la carrera de Sociología: Boletín "NoticiaS” de julio de 1994.

22 Series estadísticas publicadas por la UBA, recuperadas de: http://www.uba.ar/institucional/censos/series/default.htm

23 La caída de ingresantes también acompaña un proceso porel que progresivamente la carrera de Sociología va perdiendo espacios e importancia dentro de la estructura de la FCS. Para esto, cabe recordar que, a la hora de fundar esta nueva unidad académica, era esta carrera la que poseía más recursos (biblioteca e instituto de investigación propio y una planta administrativa) y trayectoria institucional.

24 Podemos señalar que en este último trabajo Diego Pereyra da cuenta de estas tendencias, pese a la falta de registro y el estado fragmentario de las estadísticas sobre esta cuestión, al reconstruir para las décadas de 1990 y 2000 el desempeño institucional de la disciplina -en función de las carreras y departamentos abiertos- y de su matrícula de estudiantes y graduados. Respecto de la situación de docentes e investigadores en este período, para el caso de sociología, directamente no hemos podido encontrar trabajos que puntualicen a nivel general sobre su situación.Como única excepción mencionamos el trabajo de Bizai, Harracá y Stechina (2010), el cual, sin embargo, recorta explícitamente su universo y alcance de indagación sobre el caso de los docentes e investigadores de la carrera de Sociología de la UBA a principios de la década del 2000.

25 Historia de la Agencia Nacional de Promoción Científica y Tecnológica: http://www.agencia.mincyt.gob.ar/frontend /agencia/post/556

26 Incentivo para el personal docente de las Universidades Nacionales, decreto no 2.427 del año 1993: http://servicios.inf oleg.gob.ar/infolegInternet/anexos/15000-19999/19168/norma.htm. Las mayúsculas corresponden al original.

27 Señalamos brevemente que tanto Ruth Sautu como Enrique Oteiza habían tenido una relación cercana con Germani. La primera formó parte de los cursos que este ofreció en el Colegio Libre de Estudios Superiores (CLES) en la década de 1940 -espacio que sirvió como semillero del núcleo original que impulsó la apertura de la carrera en 1957-; fue además una de las primeras becadas que, con su respaldo, pudo estudiar un posgrado en el extranjero y, asimismo, lo acompañó cuando trasladó sus proyectos de investigación al Instituto Di Tella a mediados de la década de 1960. Por su parte Oteiza, primer director del Instituto Di Tella, había mantenido vínculos personales y profesionales cuando el sociólogo romano trabajó allí.También podemos señalar que él era el director en funciones del Instituto de Investigaciones de la Facultad de Ciencias Sociales cuando, por medio de una propuesta de su Comité Académico, se gestionó su cambio de nombre en diciembre de 1993.

28 Documento institucional: boletín “NoticiaS” de la dirección de la Carrera de Sociología. 